\title{
Can cultural consumption increase future earnings? Exploring the economic returns to cultural capital
}

\author{
Working paper 20
}

February 2018

Aaron Reeves and Robert de Vries

Keywords: Earnings, hiring, cultural consumption, cultural capital, labour

market

Keywords: Earnings, hiring, cultural consumption, cultural capital, labour market

Link to working paper:

http://eprints.Ise.ac.uk/101858/1/Reeves de Vries can cultural consumption increa se future earnings wp20.pdf

More on the theme of \#LSEKnowledge

In this study, we used data from a large, nationally representative survey of the British population to determine whether participating in cultural activities has a positive effect on people's future earnings, and on their chances of promotion. In a sample of around 20,000 people, we examined the relationship between their current participation in cultural activities and their economic situation one year later. In the survey (which is called 'Understanding Society'), respondents are asked if they participated in each of a list of 14 activities, including: watching a film at the cinema, visiting an art exhibition, visiting a street art display, attending a carnival, attending the theatre, attending the opera, attending a classical music concert, and attending a rock or pop performance.

We found that people who participated in more cultural activities earned higher salaries a year later. People who participated in one additional cultural activity earned an average of $£ 175$ more per month in the subsequent year. We also found that people who participated in more cultural activities were more likely to be promoted in the subsequent year, and were more likely to be upwardly socially mobile (to move from intermediate occupations to professional and managerial occupations).

There are a number of potential reasons why people who participate in more cultural activities may earn more in the future (and be more likely to be promoted and to be upwardly mobile):

- A causal effect of cultural participation. Cultural participation may be directly beneficial. Professional gatekeepers (such as members of hiring committees) may value cultural participation in and of itself as an indication of potential 'fit' with the company; with more culturally active candidates being seen as better prospects for hiring and promotion. 
- Reverse causation. Rather than cultural participation being beneficial for earnings, people on higher earnings may be more culturally active in the first place. (This would produce a relationship between cultural participation and future earnings because what you earned last year is strongly related to what you will earn this year).

- Confounding by social background. People from more advantaged social backgrounds are more likely to be culturally active. People from more advantaged backgrounds are also more likely to end up in higher paying jobs for reasons other than their level of cultural activity. This would tend to produce an apparent association between cultural participation and future earnings.

- Confounding by intelligence or personality. Participation in a wide variety of cultural activities may be an indicator of intelligence and/or personality characteristics such as extraversion and sociability. It may be these characteristics, rather than cultural participation per se, which are beneficial.

In our statistical models, we used statistical modelling to account for these different explanations. In particular, we accounted for a variety of measures of social background, prior earnings, cognitive ability and personality. We found that, even when we remove these effects, there is still a positive effect of cultural participation on earnings and the chances of promotion and upward mobility.

Our findings suggest that these effects are strongest for those who are competing for higher status jobs, where gatekeepers may often be selecting between candidates with similar educational and occupational qualifications. Our results also suggest that the beneficial effect of cultural participation is not restricted to traditionally 'high-brow' activities, such as attending the opera or visiting art exhibitions. Participation in a variety of activities - including things like watching films at the cinema - appears to be valued.

In conclusion, the results of our study suggest that cultural participation has a significant beneficial effect on people's future economic prospects. The most likely explanation for this effect is that economic gatekeepers (such as members of hiring or promotion committees) value cultural participation as an indication of an interesting and well-rounded candidate. Our study also suggests that, when it comes to cultural participation, the message is not that only 'high-brow' activities count, but more generally that 'more is better'. 


\section{LSE International Inequalities Institute}

The International Inequalities Institute (III) based at the London School of Economics and Political Science (LSE) aims to be the world's leading centre for interdisciplinary research on inequalities and create real impact through policy solutions that tackle the issue. The Institute provides a genuinely interdisciplinary forum unlike any other, bringing together expertise from across the School and drawing on the thinking of experts from every continent across the globe to produce high quality research and innovation in the field of inequalities.

In addition to our working papers series all these these publications are available to download free from our website: www.Ise.ac.uk/III

For further information on the work of the Institute, please contact the Institute Manager, Liza Ryan at e.ryan@Ise.ac.uk

International Inequalities Institute

The London School of Economics and Political Science

Houghton Street

London

WC2A 2AE

Email: Inequalities.institute@Ise.ac.uk

Web site: www.Ise.ac.uk/III

@LSEInequalities

(c) Aaron Reeves and Robert de Vries. All rights reserved.

Short sections of text, not to exceed two paragraphs, may be quoted without explicit permission provided that full credit, including $\odot$ notice, is given to the source. 